\title{
0 assunto de obras literárias ficcionais: uma perspetiva de leitores portugueses
}

\author{
Patrícia de Almeida*
}

Artículo recibido:

3 de enero de 2020

Artículo aceptado:

5 de mayo de 2020

Artículo de investigación
Resumo

$\mathrm{O}$ assunto das obras de cariz ficcional mostra-se difícil de determinar, dadas as especificidades do texto literário. Muito embora, como apontam vários estudos, tal é necessário e possível, através de uma abordagem categorial ao assunto e tendo em consideração o contexto e os utilizadores dos serviços de informação. Assim sendo, este trabalho tem como objetivo averiguar quais as possíveis categorias constituintes do assunto em ficção, na perspetiva de utilizadores de bibliotecas, comparando-as com as apontadas pela literatura científica internacional. Para tal, realiza-se um estudo de caso de âmbito exploratório e qualitativo, numa biblioteca pública

* Faculdade de Letras, Universidade de Coimbra, Portugal

mebpatricia@gmail.com

INVESTIGACIÓN BIBLIOTECOLÓGICA, vol. 35, núm. 86, enero/marzo, 2021, México, ISSN: 2448-8321 pp. 29-44 
portuguesa. Os resultados mostram que a abordagem categorial ao assunto também serve os interesses dos leitores participantes nesta investigação, mas que nem todas as categorias apontadas nos estudos internacionais se mostram pertinentes. Afigura-se, porém, plausível o surgimento de uma outra (sub)categoria para a descrição do assunto em ficção.

Palavras-chave: Indexação; Assunto; Ficção; Portugal

La materia en las obras literarias de ficción: una perspectiva de lectores portugueses

Patrícia de Almeida

\section{RESUMEN}

La determinación de la materia en las obras de ficción es una tarea difícil debido a las especificidades del texto literario. Sin embargo, tal como señalan varios estudios, esta tarea es necesaria y posible de realizar mediante una aproximación a la materia con categorías y teniendo en cuenta el contexto y los usuarios de los servicios de información. Considerando esto, el presente artículo tiene como objetivo investigar las posibles categorías que forman parte de la materia en la ficción, desde la perspectiva de los usuarios de bibliotecas, comparándolas con aquéllas indicadas en la literatura científica internacional. Con este fin, se realizó un estudio de caso exploratorio y cualitativo en una biblioteca pública portuguesa. Los resultados muestran que la aproximación a la materia por categorías también resultó de interés para los usuarios lectores que participaron en la investigación, aunque no todas las categorías señaladas en los estudios internacionales resultaron pertinentes. Sin embargo, parece plausible la existencia de otra (sub)categoría para la descripción de la materia en ficción.

Palabras clave: Indexación; Materia; Ficción; Portugal 
The determination of subject in fictional literary works: a viewpoint of Portuguese readers Patricia de Almeida

Abstract

It is difficult to determine the subject of fictional works, due to the specific characteristics of the literary text. However, as several studies point out, this is necessary and possible through an approach to the subject, by subdividing it into categories and considering the context and the users of information services. Thus, the objective of this paper is to investigate the possible categories which form part of the subject in fiction, from the viewpoint of the library users, and to compare them with those described in the international scientific literature. To this end, an exploratory and qualitative case study was carried out in a Portuguese public library. The results show that the subdivision of the subject into categories fits the viewpoint of the readers participating in this research, but not all the categories pointed out in the international studies are relevant. However, the development of another (sub)category for the subject description of fiction seems plausible.

Keywords: Indexing; Subject; Fiction; Portugal

\section{A INDEXAÇÃO POR ASSUNTO NAS BIBLIOTECAS}

To âmbito dos serviços prestados pelas bibliotecas, um dos tópicos mais 1 relevantes é aquele que respeita à indexação, concretamente à atribuição de termos de assunto a um determinado documento, desta forma apontando ou indicando o seu conteúdo, significado, finalidade ou características (Anderson e Pérez-Carballo, 2001). Trata-se de uma prática já com alguns séculos (Witty, 1973), todavia considera-se que ganhou mais relevância a partir do século XIX, face à crescente quantidade de informação e à consequente necessidade de a organizar e de garantir o seu acesso (Silva e Fujita, 2004).

Ao longo do tempo, a indexação por assunto foi-se afirmando como um serviço essencial na generalidade das bibliotecas, já que este permite aos utilizadores recuperar a informação pretendida, mais concretamente encontrar 
o documento preciso para colmatar as suas necessidades de informação, sejam elas reais ou potenciais. Daí que seja difícil (senão mesmo impossível) encontrar, nas estantes ou nas bases de dados das bibliotecas, um documento ao qual não tenha sido atribuída uma classe e termos de assunto (Saarti, 2002). Se se gastar o tempo com a busca do documento e não com o seu uso propriamente dito, será quase certo que o utilizador não voltará a recorrer à coleção da biblioteca. Poupar o tempo do leitor é, portanto, uma questão bastante significativa, já ressaltada por Ranganathan (1931), na quarta lei para os serviços de biblioteca. Advoga-se, então, que as bibliotecas devam proporcionar aos utilizadores dos seus serviços um acesso rápido, simples e eficaz a todo o tipo de documentos e a toda a informação.

Não obstante a reconhecida importância, qualquer indexador poderá falar da grande complexidade do seu trabalho e dos inúmeros desafios colocados no ato da seleção e atribuição dos termos de assunto a um documento. Anderson (2002) contabilizou pelo menos vinte decisões importantes, respeitantes ao trabalho do indexador. Ora, se a complexidade da indexação por assunto é uma realidade para a generalidade dos documentos, sê-lo-á muito em particular para os documentos de cariz ficcional (Fedeli, 2015). Antonio e Moraes (2012) afirmam que a indexação de ficção por assunto é algo bastante difícil, especialmente por não existirem instrumentos nem abordagens metodológicas adequadas para tal, isto quando comparado com o tratamento dado aos documentos de cariz não ficcional. Em ficção, por exemplo, não se encontra facilmente um resumo ou uma introdução e os títulos não se afiguram um ponto de informação confiável em relação ao assunto, podendo ser até mesmo enganadores (Broughton, 2004). Será impraticável a leitura integral das obras literárias pelos bibliotecários ou mesmo a leitura de uma parte ${ }^{1}$, pois absorve um tempo considerável ao indexador, pouco viável para os serviços de informação com escassez de recursos. Não obstante, a análise e a recuperação de conteúdo de ficção são tópicos verdadeiramente interessantes para a Ciência da Informação, em especial devido à natureza multidimensional e interpretativa das obras literárias e ao facto de estas terem ampla utilização nas bibliotecas (Saarti, 2019).

As questões problemáticas poderão ser, pelo menos em parte, uma explicação para o facto de a tradição da Biblioteconomia ditar que um documento ficcional seja analisado pelos seus aspetos factuais e tratado pela sua forma ou género literário e não pelo seu conteúdo propriamente dito, o que

1 É o caso do modelo MENTIF (Sabbag, 2017), onde é proposta a leitura dos últimos capítulos dos romances. Contudo, considera-se que este modelo poderá ampliar os pontos de acesso ao assunto nos registos bibliográficos, o que, possivelmente, acarretará ganhos na recuperação da informação. 
fica claro quando comparado com um documento não ficcional. Veja-se o caso da Classificação Decimal Universal, por exemplo, em que a classe 8 se destina a Língua, Linguística e Literatura, sendo esta última notada com 82 e com auxiliares de forma: 82-1 para poesia, 82-31 para romance, 82-4 para ensaios... Saarti $(2002 ;$ 2019) defende que, na verdade, os sistemas classificatórios deixam intocada a descrição do conteúdo em ficção. Muito recentemente, um estudo em contexto europeu (Almeida, 2019a) mostra que são escassas as bibliotecas nacionais que proporcionam aos utilizadores dos seus catálogos em linha os termos de assunto relativos ao conteúdo do Romance literário. Em consequência, a tradição de não indexar por assunto as obras de cariz ficcional ou o enviesamento do tratamento documental pela forma/ género terão, certamente, um impacto não negligenciável na recuperação da informação e no acesso aos documentos ficcionais.

\section{O ASSUNTO NAS OBRAS LITERÁRIAS DE CARIZ FICCIONAL}

Os utilizadores de bibliotecas nem sempre possuem um conhecimento prévio da informação que procuram e dos documentos que pretendem consultar; este é um mal-entendido antigo, refere Eco (1994). No caso dos textos de cariz ficcional, a questão não só se mantém como se agrava, uma vez que, normalmente, não existem termos de assunto para a recuperação da informação.

Fedeli (2015) relata que, mesmo quando se trata de obras ficcionais, os utilizadores pesquisam a informação por assunto e que a única maneira de os bibliotecários ajudarem é socorrerem-se da sua experiência pessoal. Este não será um aconselhamento profissional e, por certo, haverá casos em que os pedidos dos utilizadores não serão devidamente atendidos, o que terá um impacto adverso não só na boa imagem dos serviços prestados pelas bibliotecas e pelos bibliotecários mas também nos hábitos de leitura em geral. Um estudo recente (Almeida, 2019b) corrobora a ideia de que a seleção de leituras literárias é maioritariamente feita na biblioteca e não em momento anterior. E, se por um lado, se reconhece o papel especializado dos profissionais da biblioteca na recomendação de leituras, por outro verifica-se serendipidade e solidão do leitor no momento da seleção de leituras. Mais relevante será o facto de, na perspetiva dos leitores, o estudo apontar o assunto da obra literária como o elemento mais importante, tanto no momento de seleção com no de recomendação de leituras. Desta feita, a indexação por assunto de textos de cariz ficcional terá, certamente, pertinência no serviços prestados pelas bibliotecas. Saarti (2019) afirma que a necessidade prática de recuperação 
de obras de cariz ficcional permaneceu inalterada, tanto para fins privados como para comerciais, enquanto as possibilidades de criação de sistemas de recuperação para a ficção aumentaram. Resta a tarefa, não menos complexa, de conseguir determinar o(s) assunto(s) das obras ficcionais.

Mesmo para indexadores mais experientes, a determinação do assunto em ficção não se afigura uma tarefa fácil, pelo menos não o será de uma forma consistente e universal. O termo assunto por si só levanta já questões que dividem a literatura da biblioteconomia. Veja-se a tradução da palavra em língua inglesa, onde coexistem "subject" e "aboutness", muito embora os dois vocábulos possam ou devam ser considerados sinónimos, como defende Hjørland (2016). O próprio conceito de assunto é também subjetivo e discutível, podendo abarcar aspetos conotativos ou denotativos, expressivos ou factuais, de significado ou de significante, de conteúdo ou de forma (Bell, 1992; Saarti, 1999; Hypén e Mäkelä, 2011). Desta feita, o assunto alcança uma multiplicidade de tópicos ou categorias possíveis.

Embora a história da análise do conteúdo de ficção seja curta e não abranja mais do que um século (Saarti, 2019), ao longo dos últimos anos, foram surgindo diversas propostas para ultrapassar o problema da determinação do assunto. A perspetiva facetada ou categorial ao que se entende por assunto parece ser a que reúne o consenso da generalidade dos investigadores. Tal é compreensível, uma vez que esta abordagem confere uma certa lógica ao difícil processo de indexação (Silva e Fujita, 2004). Por outro lado, e na ótica do entendimento diferenciado do que pode constituir o assunto, verifica-se que os investigadores já não estão em total acordo no que toca às categorias possíveis ou adequadas para a determinação do assunto em ficção. Isto mesmo poderá confirmar-se numa breve revisão dos trabalhos mais relevantes sobre esta questão, que a seguir se apresenta.

$\mathrm{Na}$ Europa nórdica, para a determinação do assunto em ficção e tendo por base estudos com utilizadores, Pejtersen (1979) sugeriu as categorias "subject-matter", "frame" (time, place, social environment, profession), "author's intention/attitude" e "accessibility". Andersson e Holst (1996) revisitaram este trabalho e apresentaram um modelo categorial com "phenomena", "frame" e "author's intention". O "Tesaurus för indexering av skönlitteratur" ("Thesaurus for the indexing of fiction" (trad. ingl.), Jansson e Södervall, 1987) propõe um sistema elaborado de categorias: "setting (time, and place)"; "persons (development, social relations, and profession/occupation)"; e "subject (ideology, action, nature, and human body)". Esta proposta inspirou projetos finlandeses (Kaunokki Finish Fiction Thasaurus, FinnONTO e Booksampo), que combinam diferentes fontes de dados com o conhecimento dos utilizadores (Saarti e Hypén, 2010; Hypén e Mäkelä, 2011). As categorias aqui indicadas 
são "genres", “events, motives, and themes", “actors", "settings", "times" e "other (technical, and typographical aspects)".

Num enquadramento norte-americano, as "American Library Association's Guidelines on Subject Access to Individual Works of Fiction, Drama, etc." (ALA, 1990) propõem como categorias do assunto em ficção "form/ genre”, "persons”, “'setting” e "topics”, bem como uma lista de palavras com mais de 20 páginas para os cabeçalhos de assunto da Library of Congress. Da sua investigação, Clare Beghtol (1994) concluiu que "characters", “events”, "spaces" e "times" seriam as categorias fundamentais para a indexação por assunto de ficção, estando presentes na generalidade das propostas.

Mais recentemente e em contexto europeu, Alenka Šauperl $(2012 ; 2013)$ propõe como categorias de assunto: "story", "time frame", "information about the author", "genre", "personal experience with reading" e "evaluation (awards, personal evaluation)”. Já Sara Fedeli (2015) aponta "genere”, "tempo”, “ambientazione”, "tema principale", "personaggi" e "forma del documento" como tópicos presentes nas obras de cariz ficcional e solicitadas pelos utilizadores de bibliotecas.

No Brasil, o modelo para indexação de ficção MENTIF (Sabbag, 2017) apresenta quatro categorias (personagem, evento, espaço e tempo), à semelhança das já referidas no modelo de Beghtol.

Uma análise rápida permitirá concluir que existem categorias consensuais e sempre presentes, nomeadamente as que dizem respeito ao enquadramento espácio-temporal, e que outras há dependentes da teoria que as suporta e do contexto. Tal não será surpreendente se se tiver em conta que o assunto não se mostra algo único e universal (Campbell, 2000), podendo obter-se um entendimento diferente consoante a comunidade em causa (Pejtersen, 1979; Anderson e Pérez-Carballo, 2001). Daí que Saarti (2019) refira que a determinação do assunto em ficção é um processo contínuo, uma interação entre o texto do escritor, o leitor e o contexto histórico-social em causa.

A indexação por assunto, em especial a de documentos de cariz ficcional, não se afigura um trabalho propriamente neutro e objetivo, nem apresenta procedimentos exatos e universais (Mai, 2001; Broughton, 2004). O trabalho do indexador deve, a todo o momento, considerar a visão e os interesses dos utilizadores dos seus serviços (Silva e Fujita, 2004). É para a satisfação das necessidades informacionais dos utilizadores que o indexador trabalha e a opinião deles poderá constituir uma espécie de garantia ao trabalho realizado pelo profissional. Portanto, públicos diferentes terão necessidades específicas que devem ser consideradas pelo indexador (Saarti, 2019). Neste sentido, os utilizadores podem colaborar no aumento da qualidade dos serviços prestados, em concreto na construção das coleções, na representação e organização da informação, sendo parte ativa na construção de soluções para 
resposta às necessidades de outros utilizadores (Alvarez e Vidotti, 2017). Recorde-se, igualmente, que um instrumento ou metodologia criados por uma autoridade epistémica poderá não estar em sintonia com as necessidades do público que se pretende servir (Albrechtsen e Pejtersen, 2000). Portanto, para satisfazer convenientemente as necessidades informacionais do público dos serviços de biblioteca, parece útil e desejável a realização de estudos com utilizadores.

Muito embora existam importantes questões problemáticas, a literatura da Biblioteconomia mostra que será possível realizar uma indexação por assunto de obras de cariz ficcional com algum grau de consistência e de replicabilidade (Saarti, 2002; Hypén e Mäkelä, 2011; Moraes, 2012; Fedeli, 2015), desta forma facilitando o acesso e a recuperação da ficção. Considera-se até que, ao longo dos últimos anos, tem havido uma atenção crescente pela indexação por assunto de ficção, muito provavelmente devido ao interesse dos utilizadores por estes documentos e devido ao potencial que as tecnologias e a inteligência artificial apresentam e ao que isso poderá trazer aos serviços prestados pelas bibliotecas e pelas plataformas comerciais.

Neste enquadramento teórico sobre a indexação por assunto de ficção e face à ausência generalizada de estudos efetivos fundamentados em contexto português, considera-se que será pertinente e útil conhecer o ponto de vista dos utilizadores de biblioteca portugueses sobre o que entendem ser o assunto da obra ficcional. Desta forma, poder-se-á abrir portas à reflexão sobre a realidade portuguesa e, possivelmente, levá-la para a discussão do tópico a nível internacional.

\section{Metodologia}

Em sequência da lacuna verificada, este trabalho tem como objetivo específico averiguar as possíveis categorias constituintes do assunto de obras de cariz ficcional, na perspetiva de utilizadores de bibliotecas em Portugal, comparando-as, posteriormente, com as apontadas pela literatura científica internacional. Assim, propõe-se um pequeno estudo de caso de âmbito exploratório e qualitativo, em contexto português. Metodologicamente, opta-se pela técnica de questionário e pelo estudo de caso, uma vez que este se evidencia como uma pesquisa empírica que investiga fenómenos contemporâneos em contexto de vida real (Yin, 2003), o que é, em verdade, o que aqui se pretende.

Para a realização da investigação, foi selecionada uma biblioteca pública municipal, localizada no norte de Portugal, e foi determinado o género literário ficcional narrativo Romance (82-31 na Classificação Decimal Universal). 
A ficção será o tipo de literatura mais popular, especialmente nas bibliotecas públicas (Saarti, 2019). Dadas as suas especificidades, o Romance será o género mais procurado e requisitado ${ }^{2}$ para a leitura domiciliária e, por certo, o mais complexo, no que ao texto narrativo diz respeito. A escolha da biblioteca explica-se por pertencer à tipologia mais acessível ao público em geral e por ali se obter a autorização e a colaboração das entidades municipais, sem as quais a investigação não seria possível. Assim sendo, o estudo concretiza-se com dados provenientes de uma amostra por conveniência.

Com a colaboração dos recursos humanos afetos à biblioteca, foi solicitado aos utilizadores que preenchessem um breve questionário, no momento de devolução de um Romance previamente requisitado para leitura domiciliária. A participação no estudo foi voluntária e anónima, informando-se que a finalidade seria obter a livre opinião dos leitores (pelo que não existiriam respostas certas ou erradas) e que os dados recolhidos seriam considerados confidenciais. Muito embora não se tenha obtido um número massivo de participações, o cariz voluntário evitou constrangimentos e respostas de circunstância, possíveis enviesamentos da investigação. Considera-se, portanto, que os dados obtidos são fidedignos e em número analisável, sem recurso a tecnologia digital.

O questionário solicitou dados relativos a:.

- idade, sexo e habilitações literárias, a fim de se apurar a diversidade ou não dos leitores participantes na investigação;

- título e autoria do Romance, para validação do género literário e certificação da variedade ou não de obras ficcionais;

- assunto do Romance, mediante o preenchimento de espaços (máximo 20) com palavras ou expressões livres (nunca frases), que respondessem à questão simples e direta "Assunto - O Romance que acabou de ler é sobre...?”.

Os dados obtidos foram alvo de uma análise de conteúdo. Esta consiste numa interpretação do significado de determinada informação, textual ou visual, que se organiza em temas ou categorias, podendo abranger desde uma descrição superficial até uma profunda interpretação dos discursos (Leung e Chung, 2018). Nesta investigação, realiza-se uma análise de conteúdo categorial, em conformidade com o objetivo traçado. Os dados obtidos são apresentados de forma englobada e transcritos para quadros, permitindo uma leitura analítica e comparativa com as categorias de assunto das obras

2 Este pressuposto foi confirmado pela Coordenadora da Biblioteca onde se realizou o estudo de caso. 
de cariz ficcional apontadas na literatura científica internacional, estas traduzidas para Língua Portuguesa.

\section{Apresentação E ANÁlise dos RESUltados}

Neste estudo participaram 23 leitores, com idades compreendidas entre os 16 e os 87 anos, sendo 2 do sexo masculino e 21 do sexo feminino e possuindo habilitações literárias desde o 4 . $^{\circ}$ ano a curso de mestrado. Face a estes dados e com exceção da questão de género, verifica-se a diversidade de públicos e considera-se a amostra representativa, embora pequena. Os questionários tiveram por base 23 Romances, de 15 escritores portugueses e estrangeiros. Salienta-se o facto de não existirem várias respostas para um mesmo Romance, o que permitiria um secundário mas muito pertinente estudo comparativo.

Na questão relativa ao assunto do Romance, verifica-se a atribuição de um número variável de palavras - entre 2 e 8 , sendo 4 palavras a opção mais frequente. Num total de 94 palavras, constata-se que todas parecem pertencer à classe gramatical Nome, com a exceção da palavra "batalhar", aparentemente Verbo. Tal não será surpreendente, uma vez que é a classe que gramaticalmente denomina realidades (pessoas, objetos, sensações, sentimentos...).

Estas palavras foram distribuídas tendo por referência as categorias de assunto de obras de cariz ficcional elencadas na literatura científica mais relevante, a fim de se estabelecerem possíveis paralelismos. Estando em presença de uma espécie de sistema categorial pré-definido, inclui-se também "Outra" como categoria aberta, para elementos possivelmente não enquadráveis nas categorias existentes. O número de vezes que uma palavra foi utilizada como assunto surge representado após a mesma e entre parênteses curvos. Os resultados encontram-se listados no Quadro 1.

Dadas as características da Língua Portuguesa ${ }^{3}$, algumas palavras suscitaram dúvidas no que toca à sua inserção de forma clara numa das classes pré-estabelecidas, podendo distribuir-se por várias, como se mostra no quadro seguinte (Quadro 2). Para esclarecimento cabal destes casos dúbios, os utilizadores teriam de ser especificamente questionados sobre a intencionalidade e a semântica dos vocábulos.

3 Considera-se a Língua Portuguesa algo propensa a polissemia e homonímia, ponto problemático no que respeita aos termos de assunto para indexação. Por exemplo, face à língua inglesa, verifica-se que "história" poderá corresponder a "history" ou a "story"; "romance" poderá significar "novel - a long printed story" ou "romance - relationship of love between people". 


\begin{tabular}{|c|c|c|}
\hline \multicolumn{2}{|c|}{ Categorias } & “Assunto - 0 romance que acabou de ler é sobre...?" \\
\hline \multicolumn{2}{|l|}{ Forma/Género } & Ficção; Alegoria \\
\hline \multicolumn{2}{|c|}{ Pessoas/Personagens } & Jovem; Espiões; Marquesa; Rainha; Jesus; José; Maria \\
\hline \multirow{2}{*}{$\begin{array}{l}\text { Contexto/ } \\
\text { Enquadramento }\end{array}$} & Tempo & Século XVIII \\
\hline & Espaço & Alorna; Corte \\
\hline \multicolumn{2}{|c|}{$\begin{array}{l}\text { Tópicos/ Matéria/ Eventos/ } \\
\text { História/Tema }\end{array}$} & $\begin{array}{l}\text { Espionagem (2); Amor (16); Desemprego; Acidente; Morte (3); Paixão } \\
\text { (7); Traição; Devoção; Mundo (2); Realidade; Conquista; Magia; } \\
\text { Felicidade; Coragem (3); Batalhar; Perda; Esperança; Vida; Encontros; } \\
\text { Desencontros; Fé; Amizade; Vidas; Cegueira; Humanidade; Civismo; } \\
\text { Dor; Guerra; Derrota; Intriga; Separação; Erotismo (2); Sensualidade; } \\
\text { Segredos; Dogma; Tradição; Ateísmo; Religião }\end{array}$ \\
\hline \multicolumn{2}{|c|}{ Intenção/Atitude do autor } & - \\
\hline \multicolumn{2}{|l|}{$\begin{array}{l}\text { Acessibilidade } \\
\text { (legibilidade) }\end{array}$} & - \\
\hline \multicolumn{2}{|c|}{ Experiência pessoal de leitura } & - \\
\hline \multicolumn{2}{|l|}{ Avaliação } & - \\
\hline \multicolumn{2}{|c|}{ Formato do documento } & - \\
\hline \multicolumn{2}{|l|}{ Outra } & - \\
\hline
\end{tabular}

Quadro 1. Resultados do estudo por categoria

\begin{tabular}{|l|c|c|c|c|c|}
\hline Casos Dúbios & $\begin{array}{c}\text { Forma/ } \\
\text { Género }\end{array}$ & $\begin{array}{c}\text { Matéria/ } \\
\text { Evento }\end{array}$ & Personagem & $\begin{array}{c}\text { Autor (intenção/ } \\
\text { atitude) }\end{array}$ & $\begin{array}{c}\text { Experiência } \\
\text { pessoal de } \\
\text { leitura }\end{array}$ \\
\hline História (2) & $\mathrm{X}$ & $\mathrm{X}$ & - & - & - \\
\hline Família (4) & - & $\mathrm{X}$ & $\mathrm{X}$ & - & - \\
\hline Memórias & $\mathrm{X}$ & $\mathrm{X}$ & - & - & - \\
\hline Romantismo & $\mathrm{X}$ & $\mathrm{X}$ & - & $\mathrm{X}$ & $\mathrm{X}$ \\
\hline Reflexão & $\mathrm{X}$ & $\mathrm{X}$ & - & - & - \\
\hline Romance & $\mathrm{X}$ & $\mathrm{X}$ & - & - & $\mathrm{X}$ \\
\hline Suspense & $\mathrm{X}$ & - & - & $\mathrm{X}$ & - \\
\hline Ironia & $\mathrm{X}$ & $\mathrm{X}$ & - & - & $\mathrm{X}$ \\
\hline Emoção & - & $\mathrm{X}$ & - & - & - \\
\hline
\end{tabular}

Quadro 2. Casos dúbios do estudo 
$\mathrm{Na}$ globalidade dos resultados, poder-se-á concluir que existe pouca atenção destes leitores para a categoria Forma/Género, talvez por se tratar de informação já fornecida pela classificação documental, como é o caso de "ficção". Pelo contrário, a categoria Pessoas/Personagens merece maior atenção, encontrando-se informação com nome próprio ("Maria"), com estatuto social ("Rainha"), com quantidade singular ("jovem") e coletiva ("espiões").

Verifica-se que os leitores de Romances que participaram neste estudo não são muito sensíveis ao enquadramento Espaço e Tempo, o que poderá ser algo surpreendente se se recordar que esta(s) categoria(s) marca(m) presença constante na literatura da Biblioteconomia sobre o assunto de obras de cariz ficcional narrativo e que também são categorias do texto narrativo, no âmbito dos estudos literários ${ }^{4}$. Aqui, constata-se apenas a referência a um tempo bastante alargado ("Século XVIII"), a uma localização geográfica ("Alorna") e a um espaço social ("corte").

$\mathrm{Na}$ categoria relacionada com Matéria/Tema/Tópicos/Eventos/História, e tendo em conta o seu caráter abrangente e generalista, foram incluídas todas as palavras que não encontraram enquadramento nas restantes classes, o que explica o seu número mais alargado. No entanto, ao analisar este conjunto de palavras em particular, parece detetar-se a existência de alguns sememas ${ }^{5}$ distintivos. Assim, palavras como "acidente", "traição", "perda", "derrota" aparentam decorrer de ações concretas ocorridas no enredo do Romance e não se encontram na mesma esfera de assunto de palavras como "amor", "vidas", "mundo", "tradição", estas mais panorâmicas e abstratas. Considera-se que, nesta categoria em particular, talvez fosse útil aprofundar a granularidade do assunto, sendo viável uma outra categoria (ou sub-categoria) que permitisse distinguir aquele assunto procedente de ações e momentos específicos de enredo do outro assunto amplo e resultado global da trama narrativa.

Contrariamente a algumas sugestões de categoria apontadas pela literatura internacional, não se detetaram marcas claras da Intenção/Atitude do autor e da Experiência pessoal de leitura, apenas dois a três casos de caráter duvidoso. Por exemplo, a palavras "reflexão" poderá indicar que o Romance é sobre uma reflexão do autor ou até das personagens, ou que está escrito sob a forma de reflexão ou que propiciou a reflexão do leitor. Também não se distinguiram visivelmente outras categorias além das apontadas na literatura da Biblioteconomia, nem referências à Acessibilidade da leitura para os diferentes públicos. Muito provavelmente porque a leitura dos Romances se deu em

4 Consideram-se categorias da narrativa: ação, tempo, espaço, personagens, narrador e narratário.

5 Entende-se o lexema enquanto unidade com informação morfológica e semântica de mais alto nível. O semema será o somatório dos semas que formam o significado global do lexema e dele se distingue pela representação do seu conteúdo semântico. 
formato papel, não existem referências ao Formato do documento. A categoria Avaliação também não foi alvo da atenção dos leitores, muito embora, saliente-se, três Romances lidos sejam da autoria de dois escritores galardoados com o Prémio Nobel da Literatura.

Posto isto, poderá concluir-se que, de uma forma global, a abordagem categorial ao assunto de obras de cariz ficcional serve os interesses dos leitores participantes neste estudo. A análise dos dados permitiu verificar que, na perspetiva destes utilizadores portugueses de biblioteca pública municipal, o assunto de Romances é alicerçado, essencialmente, em quatro categorias já apontados por estudos internacionais, a saber: Forma/Género; Pessoas/Personagens; Contexto/Enquadramento (Tempo/Espaço); e, sobretudo, Tópicos/Matéria/Eventos/História/Tema. Mais se apurou que a abrangência e a granulosidade deste último tópico permitirão o possível surgimento de uma nova categoria de assunto em ficção.

\section{CONSIDERAÇÕES FINAIS}

$\mathrm{Na}$ generalidade das bibliotecas, o assunto dos documentos de cariz ficcional mostra-se difícil de determinar, dadas as características inerentes ao texto literário. No entanto, tal é possível e necessário, como mostra a literatura internacional da Biblioteconomia. Para tal, deverão ser tidos em consideração o contexto e os utilizadores dos serviços de informação. Até ao momento, não se conhece uma linha de estudos que reflita a realidade portuguesa, especificamente estudos de utilizadores sobre o assunto de obras de cariz ficcional. Assim, esta investigação tem algum mérito ao trazer para a discussão internacional a contribuição de uma parte do público português leitor de Romances.

Trata-se, contudo, de um pequeno estudo, com limitações de amostra, pelo que os resultados obtidos e a sua análise deverão ser enquadrados no escopo particular deste trabalho e deles não se infere informação geral, antes pistas a seguir sobre as categorias de assunto na perspetiva de leitores portugueses. E este será o principal problema dos estudos de indexação de ficção: identificar os aspetos que são relevantes e proveitosos para os utilizadores e que, por isso, merecem o esforço dos serviços de informação para serem indexados. Lembra Saarti (2019) que há muito trabalho a ser feito no desenvolvimento de melhores sistemas de informação para lidar com a ficção.

Assim sendo, para melhorar os serviços prestados a todos os leitores de ficção, considera-se fundamental mais investigação sobre o tema da indexação por assunto de obras literárias de cariz ficcional. Uma investigação adicional e mais alargada será essencial no contexto português, uma vez que escasseiam 
estudos e que os resultados do presente trabalho se encontram limitados pelos números da amostra.

Agradecimentos

A autora gostaria de agradecer às entidades municipais a autorização para a realização deste estudo, bem como a preciosa colaboração da Coordenadora da Biblioteca e de todos os leitores anónimos que responderam ao questionário.

\section{REFERÊNCIAS}

ALA (American Library Association). 1990. Guidelines on subject access to individual works of fiction, drama, etc. Chicago: ALA.

Albrechtsen, Hanne e Annelise Pejtersen. 2000. "Bringing Classifications Closer to Home: The Design of Ecological Classification Schemes for Cooperative Work”. International Workshop on Classification Schemes in Cooperative Work, Philadelphia, december 2000.

Almeida, Patrícia de. 2019a. "Tendencias europeas en la indización por asunto de ficción narrativa”. Anales de Documentación 22 (1): 1-10.

https://doi.org/10.6018/analesdoc.22.1.339791

Almeida, Patrícia de. 2019b. "Del procés de tria a la prescripció de lectures literàries a la biblioteca". BiD: textos universitaris de biblioteconomia i documentació, 42. http://dx.doi.org/10.1344/BiD2019.42.19

Alvarez, Edgar e Silvana Vidotti. 2017. "Sistemas de Recomendação para Centros de Recursos para el Aprendizaje y la Investigación”. Informação E Tecnologia 4 (2): 46-62. https://doi.org/10.22478/ufpb.2358-3908.2017v4n2.40537

Anderson, James. 2002. "Indexing, teaching of See: Information retrieval design". The Indexer 23 (1): 2-7. https://www.theindexer.org/files/23-1/23-1_002.pdf

Anderson, James e José Pérez-Carballo. 2001. "The nature of indexing: how humans and machines analyse messages and texts for retrieval. Part I: Research, and the nature of human indexing". Information Processing and Management 37 (2):231-254. http://citeseerx.ist.psu.edu/viewdoc/download?doi=10.1.1.118.5450\&rep=rep1\&type $=$ pdf

Andersson, Rolf e Erik Holst. 1996. "Indexes and Other Depictions of Fiction: A New Model for Analysis Empirically Tested". Swedish Library Research/Svensk biblioteksforskning 2-3: 77-95.

Antonio, Deise e João Moraes. 2012. "Análise documental de obras de ficção: a indexação na perspectiva do percurso gerativo de sentido", em Desafios e perspectivas cientificas para a organização e representação do conbecimento na atualidade, editado por José Guimarães e Vera Dodebei, 45-48. Marília: ISKO; Brasil-FUNDEPE. 
Beghtol, Clare. 1994. The Classification of Fiction: The Development of a System Based on Theoretical Principles. Metuchen: Scarecrow Press.

Bell, Hazel. 1992. "Should fiction be indexed? The indexability of text". The Indexer 18 (2): 83-86.

https://www.theindexer.org/files/18-2/18-2_083.pdf

Broughton, Vanda. 2004. Essential classification. London: Facet Publishing.

Campbell, Donald Grant. 2000. "Queer theory and the creation of contextual subject access tools for gay and lesbian communities". Knowledge Organization 27 (3): 122-131.

Eco, Umberto. 1994. A Biblioteca. Lisboa: Difel.

Fedeli, Sara. 2015. "La soggettazione della narrativa per bambini e ragazzi". Italian Journal of Library, Archives, and Information Science 6 (3): 101-120. https://dialnet.unirioja.es/servlet/articulo? codigo $=5226796$

Hjørland, Birger. 2016. "Subject (of documents)". ISKO Encyclopedla of Knowledge Organization.

http://www.lsko.org/cyclo/subject

Hypén, Kaisa e Eetu Mäkelä. 2011. "An ideal model for an information system for fiction and its application: Kirjasampo and Semantic Web”. Library Review 60 (4): 279-292.

https:/www.emerald.com/insight/content/doi/10.1108/00242531111127848/full/html

Jansson, Eiler e Bo Södervall. 1987. Tesaurus för indexering av skönlitteratur. Examensarbete. Borås: Högsk.

Leung, Doris e Betty Chung. 2018. "Content Analysis: Using Critical Realism to Extend Its Utility”, em Handbook of Research Methods in Health Social Sciences, editado por Pranee Liamputtong, 827-841. Singapore: Springer.

Mai, Jens-Erik. 2001. "Semiotics and indexing: an analysis of the subject indexing process". Journal of Documentation 57 (5): 591-622.

https://pdfs.semanticscholar.org/e319/66f6b33e0468e269ce5d2a245dc96774535c.pdf

Moraes, João. 2012. "Aboutness in Fiction: Methodological Perspectives for Knowledge Organization", em Advances in Knowledge Organization - Proceedings of the Twelfth International ISKO Conference, editado por Arashanipalai Neelameghan e K. S. Raghavan, 242-248. Mysore: Ergon Verlag.

Pejtersen, Annalise. 1979. "The meaning of'about'in fiction indexing and retrieval". ASLIB Proceedings 31 (5): 251-257.

Ranganathan, Siyali Ramamrita. 1931. Five Laws of Library Science. Madras: Madras Library Association.

Saarti, Jarmo. 1999. "Fiction indexing and the development of fiction thesauri". Journal of Librarianship and Information Science 31 (2): 85-92.

https://doi.org/10.1177\%2F096100069903100203

Saarti, Jarmo. 2002. Aspects and methods of fictional literature knowledge organization. Roma: Consiglio Nazionale delle Ricerche, Istituto per le Previsioni e le Ricerche Internazionali.

http://citeseerx.ist.psu.edu/viewdoc/download?doi=10.1.1.103.1036\&rep=rep1\&type $=$ pdf 
Saarti, Jarmo. 2019. "Fictional literature, classification and indexing". Knowledge Organization 46 (4): 320-332.

Saarti, Jarmo e Kaisa Hypén. 2010. "From thesaurus to ontology: the development of the Kaunokki Finnish fiction thesaurus". The Indexer 28 (2): 50-58. https://online.liverpooluniversitypress.co.uk/doi/pdf/10.3828/indexer.2010.15

Sabbag, Deise. 2017. "Orientações para uso do MENTIF (Metodologia para Indexação de Ficção)”, em Manual de política de indexação para as bibliotecas universitárias da Unesp, coordenado por Mariângela Fujita, 19-21. S. Paulo: Unesp. https://www.biblioteca.unesp.br/portal/arquivos/manual-politica-indexacao-2017.pdf

Šauperl, Alenka. 2012. "Pinning down a novel: characteristics of literary works as perceived by readers". Library Review 61 (4): 286-303. https://doi.org/10.1108/00242531211267581

Šauperl, Alenka. 2013. "Four Views of a Novel: Characteristics of Novels as Described by Publishers, Librarians, Literary Theorists, and Readers". Cataloging $\mathcal{E}$ Classification Quarterly 51 (6): 624-654. https://doi.org/10.1080/01639374.2013.773953

Silva, Maria Remédios e Mariângela Lopes Fujita. 2004. "A prática de indexação: análise da evolução de tendências teóricas e metodológicas”. Transinformação 16 (2): 133-161. http://hdl.handle.net/11449/114455

Witty, Francis. 1973. "The beginnings of indexing and abstracting: some notes towards a history of indexing and abstracting in antiquity and the middle ages". The Indexer 8 (4): 193-198. https://www.theindexer.org/files/08-4/08-4_193.pdf

Yin, Robert. 2003. Estudo de caso. Planejamento e métodos. Porto Alegre: Bookman.

Para citar este texto:

Almeida, Patrícia de. 2021. "O assunto de obras literárias ficcionais: uma perspetiva de leitores portugueses". Investigación Bibliotecológica: archivonomía, bibliotecología e información 35 (86): 29-44. http://dx.doi.org/10.22201/iibi.24488321xe.2021.86.58236 